\title{
ESTUDO PRELIMINAR, PRINCIPALMENTE DO PLÂNCTON, DAs ÄGUAS dA BAía de TODOS OS SANTOS *
}

\author{
JUAREZ JORGE SANTOS ** \\ Laboratório de Biologia Marinha - U.F.Ba.; Instituto \\ Oceanográfico e Dept. ${ }^{\circ}$ de Zoologia, Inst. Biociências - \\ U.S.P
}

SUMÃRIO

$\mathrm{O}$ estudo preliminar das águas nos $800 \mathrm{~km}^{2}$ de área da Baía de Todos os Santos (Bahia) inclui uma introdução contendo o levantamento da literatura sobre o plâncton coletado na região e adjacências, os métodos usados para obter informações acerca de alguns dados meteorológicos, hiđrológicos e hidrográficos, e sobre o fitoplâncton e zooplâncton da área. Os resultados do estudo de 17 amostras de plâncton coletadas em diferentes pontos dentro da baía são discutidos e comparados com os obtidos de outras águas ao longo da costa brasileira e em Porto Rico. A água que ocupa quase toda a baía é costeira enriquecida pelos nutrientes drenados do continente. O plâncton é relativamente mais rico em formas menores dentro da baía, do que ao largo da costa.

A Baía tem uma estrutura planctônica, tipicamente nerítica, na qual predominam as formas costeiras, junto com espécies estuarinas.

PRELIMINARY STUDY, WITH EMPHASIS ON PLANKTON, OF THE WATERS FROM THE TODOS OS SANTOS BAY

\section{SUMMARY}

A preliminary study of the waters in the $800 \mathrm{~km}^{2}$ area of the Baía de Todos os Santos (Brazil) includes an introductory survey of the literature on the plankton collected in the region and adjacencies, the methods used for obtaining information on some meteorological, hydrological and hydrographical data, and on the phytoplankton and the zooplankton of the area. The results of the study of 17 plankton samples taken in different points inside the bay are discussed and compared with those obtained from other waters along the Brazilian coast and in Puerto Rico. The water which occupies most of the bay is the coastal water enriched by the nutrients drained from the continent. The plankton is proportionally richer with smaller forms inside the bay, than outside, off the coast.

The bay contains a planktonic typically neritic structure in which the coastal forms predominate, together with estuarine species.

\footnotetext{
* Parte da memória apresentada para obter o título de Mestre em Zoologia pelo Inst. Biociências da Universidade de S. Paulo.

** Endereço atual: Instituto de Biologia - Univ. Fed. Bahia - Salvador, Ba.
}

Número especial em homenagem ao Prof. Dr. Paulo Sawaya, no ano jubilar de seu magistério. 


\section{INTRODUÇÃO}

A Baia de Todos os Santos compreende uma região nerítica de proporções consideráveis, cuja descrição geográfica se encontra no DH1 Roteiro Brasil (Ministério da Marinha, 1965).

A escassez de dados planctônicos para uma região bem estudada geopetrograficamente e a hipótese inicialmente levantada por mim de que a Baia teria um "standing-stock" de plâncton mais elevado que as regiōes costeiras adjacentes, induziram-me à presente pesquisa.

Poucos dados foram registrados até agora com referência ao plâncton de águas interiores da Baía de Todos os Santos. As grandes expedições oceanográficas coletaram na maioria das vezes ao largo da Baía em mar aberto e sobre a plataforma continental.

O cruzeiro do "Challenger" (1873-1876) fez em setembro de 1873 (Tizard et al., 1885) dragagens no interior da Baía e uma coleta (estação 129), defronte à Baía em mar aberto, contudo, não foram citadas coletas de plâncton nos trabalhos, nem foi registrado plâncton nesta área. A expedição "Albatross" (Atlântico Sul, 1887-1888) realizou uma estação ao norte da Bahia em mar aberto, lat. $12^{\circ} 07^{\prime}$ S e long. $37^{\circ} 17^{\prime} \mathrm{W}$ (Wilson, 1950).

Zimmermann (1916) apresenta um trabalho sobre as diatomáceas coletadas em alguns trechos da Baía de Todos os Santos.

Peters (1932), Klevenhusen (1933), Kasler (1938), Leloup e Hentschel (1935), Hentschel (1933), apresentam dados do cruzeiro "Meteor" (1925-27) com citações para a costa da Bahía (estações 204, 205, 206). Dentre os cruzeiros oceanográficos realizados na costa do Brasil por navios da Marinha de Guerra brasileira, foi feito em 1959 pelo N/Oc "Almirante Saldanha" um perfil ao norte da barra da Baía na latitude $13^{\circ} \mathrm{S}$ até a longitude $30^{\circ} \mathrm{W}$, com estações oceanográficas desde a plataforma continental até o mar aberto, onde foram realizadas coletas de plâncton cujos dados ainda não foram publicados (DG 06-XI - Ministério da Marinha, 1960). Ao sul da Baía foi feito também em 1957 pelo N/Oc "Almirante Saldanha" um perfil em mar aberto, da costa de Camamú (DG 20-III - Ministério da Marinha, 1969). Também os dados sobre o plâncton coletado não foram punblicados até hoje.

Gaudy (1963) faz referência aos copépodos cuja presença foi registrada durante a expedição do "Calypso" em 1962, defronte à Baía, sobre a plataforma continental. 
Björnberg (1965) apresenta a distribuição de copépodos coletados pelo cruzeiro do "M. Lomonosov" em 1962 ao largo da costa do Brasil, referindo-se às coletas feitas ao norte da Baía em mar aberto.

Portanto, exceção feita dos trabalhos de Zimmermann (1916), os quais se referem ao fitoplâncton, constitui uma lacuna na ciência brasileira a falta de dados sobre o zooplâncton e os fatores ecológicos que possam influenciar sua produção dentro da Baía de Todos os Santos. Como todas as baías de grande extensão, esta será provavelmente um viveiro de peixes, como já foi verificado para outras áreas semelhantes da costa do Brasil, tais como a lagoa dos Patos (RS) e a região lagunar de Cananéia (SP). Mais uma razão portanto para a realização de pesquisas que conduzam finalmente ao conhecimento perfeito da produtividade e dos ciclos anuais do zooplâncton na Baía de Todos os Santos.

Este trabalho é um primeiro esforço neste sentido. Tentarei nas páginas que seguem registrar alguns dos numerosos dados que venho observando desde 1969. Poucas são as interpretações possíveis porque as amostras foram tomadas durante pouco tempo. $\mathrm{O}$ trabalho por isso é mais um simples levantamento destinado a descrever hidrográfica e planctonicamente a região, fornecendo bases para pesquisas futuras.

\section{MATERIAL E MÉTODOS}

\section{A) No campo}

As coletas de plâncton foram realizadas em pontos fixos (Mapa 1) na Baía de Todos os Santos, durante os períodos de junho-julho de 1969 (inverno), janeiro-fevereiro de 1970 (verão) e julho-agosto de 1970 (inverno), durante a preamar ou baixa-mar. As estações oceanográficas foram realizadas no interior da baía com exceção de uma, feita para fins comparativos no litoral de Lauro de Freitas (Ba). Destas foram utilizadas para o presente trabalho apenas as amostras relacionadas nas Tabelas 1 a 5 .

Em cada estação oceanográfica foram tomados dados de meteorologia, hidrografia, qualidade do fundo e plâncton.

1) Meteorologia (Tab. 1): Foram anotados condições de tempo, tipo de céu, temperatura do ar, direção do vento e visibilidade do 
ar. A temperatura do ar foi medida em todas as coletas com termômetro de laboratório, de escala 0 a $50^{\circ} \mathrm{C}$, e a direção do vento foi determinada com bússola de campo (comum).

2) Hidrologia (Tabs. 2 e 3 ): Foram anotados profundidade local, estado do mar, profundidade de coleta, temperatura da água, na superfície e na profundidade, oxigênio da água na superfície e na profundidade, $\mathrm{pH}$ da água na superfície e na profundidade, salinidade da água na superfície na profundidade, material em suspensão, na superfície e na profundidade, altura da maré, transparência da água, cor da água e direção da correnteza superficial. A profundidade nas estações oceanográficas foi medida através de cabo batimétrico, compa-

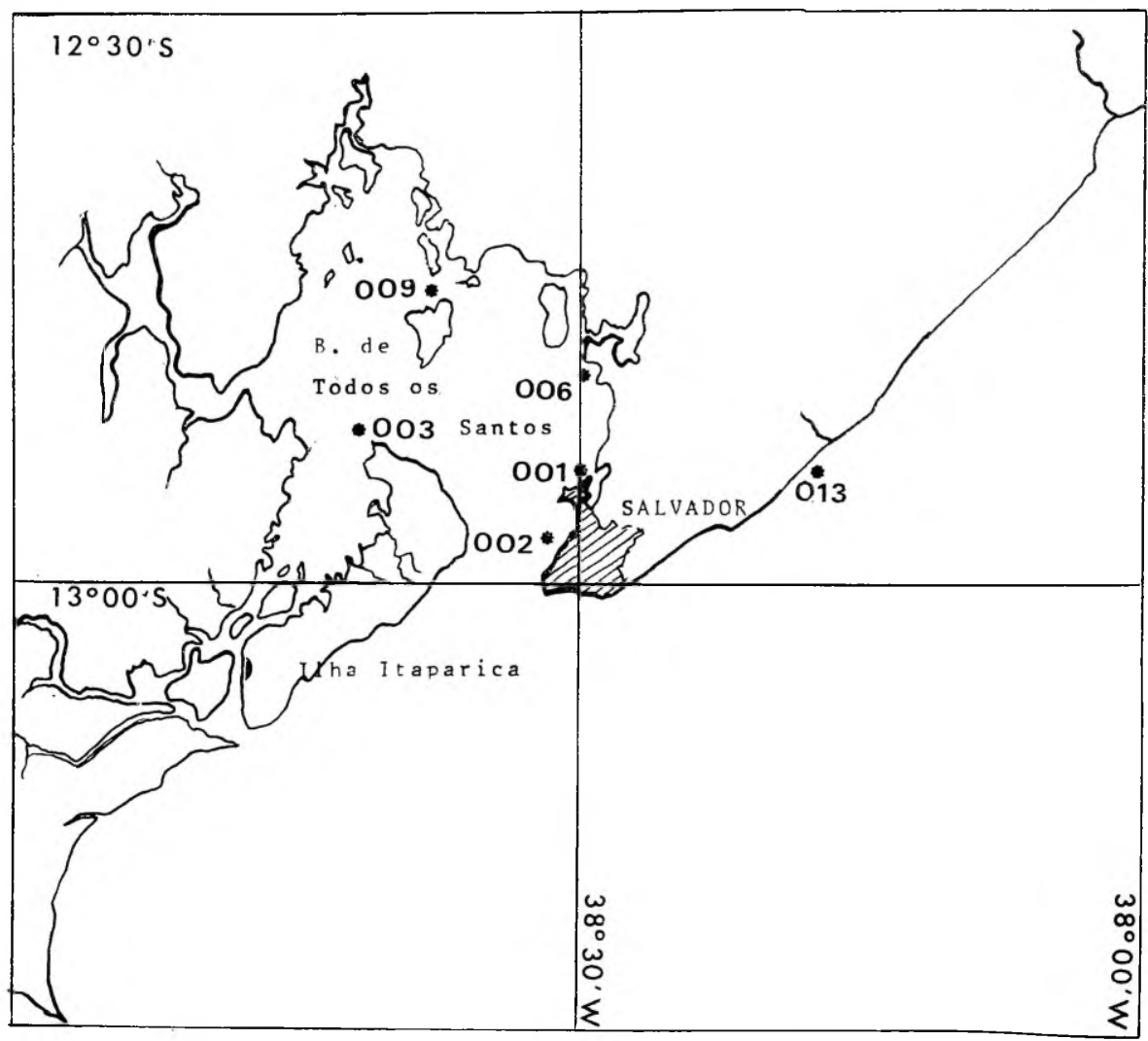

$$
\begin{aligned}
& \text { Mapa 1: Baía de Todos os Santos com indicação } \\
& \text { das estações de coleta }
\end{aligned}
$$


rando-a com profundidades assinaladas nas cartas náuticas do DHN (Marinha de Guerra) para a região. A temperatura da água na superfície e profundidade foi medida com termômetro hidrográfico marca Gemware (GM manufacturing Co. - N. York). As amostras de água tanto na superfície como na profundidade para determinação do $\mathrm{pH}$, oxigênio, salinidade e material em suspensão foram coletadas com garrafa hidrográfica de Nansen e Van Dorn (PVC) (marca Gemware - G. M. Manufacturing Co. - New York). O pH foi determinado no campo, pelo método colorimétrico com papel indicador Merck. As amostras de oxigênio e material em suspensão foram fixadas no campo. Como as coletas foram realizadas nas amplitudes de préamar ou baixamar, a altura da maré foi registrada diretamente das tábuas de marés da DHN (Ministério da Marinha, 1969, 1970). A transparência da água foi determinada através do disco de Secchi, a cor foi determinada grosseiramente; a direção da correnteza superficial foi obtida através de uma bússola de campo (comum).

3) Qualidade do fundo: Foi anotada no campo, analizando grosseiramente, a textura da amostra de fundo, tomada pelo cabo batimétrico e disco de Secchi. Os dados foram comparados com os assinalados nas cartas náuticas da DHN.

4) Plâncton: Foi coletado, em superfície e profundidade (Tab. 8) com a garrafa de Nansen e Van Dorn (Marca Gemware - G.M. Manufacturing Co., New York), para o fitoplâncton total; rede de plâncton de malha fina (180 e $208 \mu$ de abertura de malha) com diâmetro de boca de $27 \mathrm{~cm}$, para coleta de "Fitoplâncton" superficial; redes de plâncton de malha grossa $(280 \mu)$ com diâmetro de boca de 20 e $50 \mathrm{~cm}$ para coleta de "Zooplâncton" superficial. As amostras de fitoplâncton total foram fixadas com lugol. Todas as amostras das coletas de plâncton, com exceção das de fitoplâncton total, foram fixadas em formalina $40 \%$, misturando 1 parte desta formalina em 9 partes da água da amostra.

\section{B) No laboratório}

1) Hidrologia (Tab. 2) : A determinação do oxigênio dissolvido foi feita pelo método de Winkler. A salinidade, pelo método de Harvey (1955) e salinômetro (marca Beckman 2). A determinação do Material em Suspensão na água do mar foi realizada pela técnica de incineração da matéria orgânica total, cujos resultados são expressos em 
densidade de matéria orgânica e inorgânica por volume de água filtrado (segundo Fox, Isaacs e Corcoran, 1952, in Teixeira e Kutner, 1962).

2) Plâncton: As amostras de fitoplâncton total, após sedimentação em cubetas volumétricas, foram analisadas ao microscópio invertido de Utermohl para a determinação do "standing-stock" do fitoplâncton (nano e microfitoplâncton).

De todas as amostras coletadas com rede foram inicialmente retiradas subamostras com a pipeta Stempel $\left(2,5 \mathrm{~cm}^{3} / 250 \mathrm{~cm}^{3}\right)$ contados todos os indivíduos e analisada qualitativamente o restante da amostra, com o microscópio estereoscópico.

Os resultados das coletas horizontais são expressos em porcentagem da quantidade total de indivíduos na amostra.

3) A determinação sistemática dos copépodos e alguns outros planctontes foi feita mediante dissecção dos apêndices, imersos em glicerina sobre uma lâmina e cobertos com lamínula. Os desenhos foram feitos com câmara clara Zeiss.

\section{RESULTADOS}

Todos os dados que constam das tabelas a seguir correspondem apenas à amostras e observações analisadas para o presente estudo, ficando as demais e outras que lhes serão acrescentadas, para outro trabalho a ser feito no futuro.

A precipitação pluvial em 1970 variou entre 69,4 e $244,0 \mathrm{~mm}$ na cidade de Salvador (Estação Meteorológica de Ondina). 


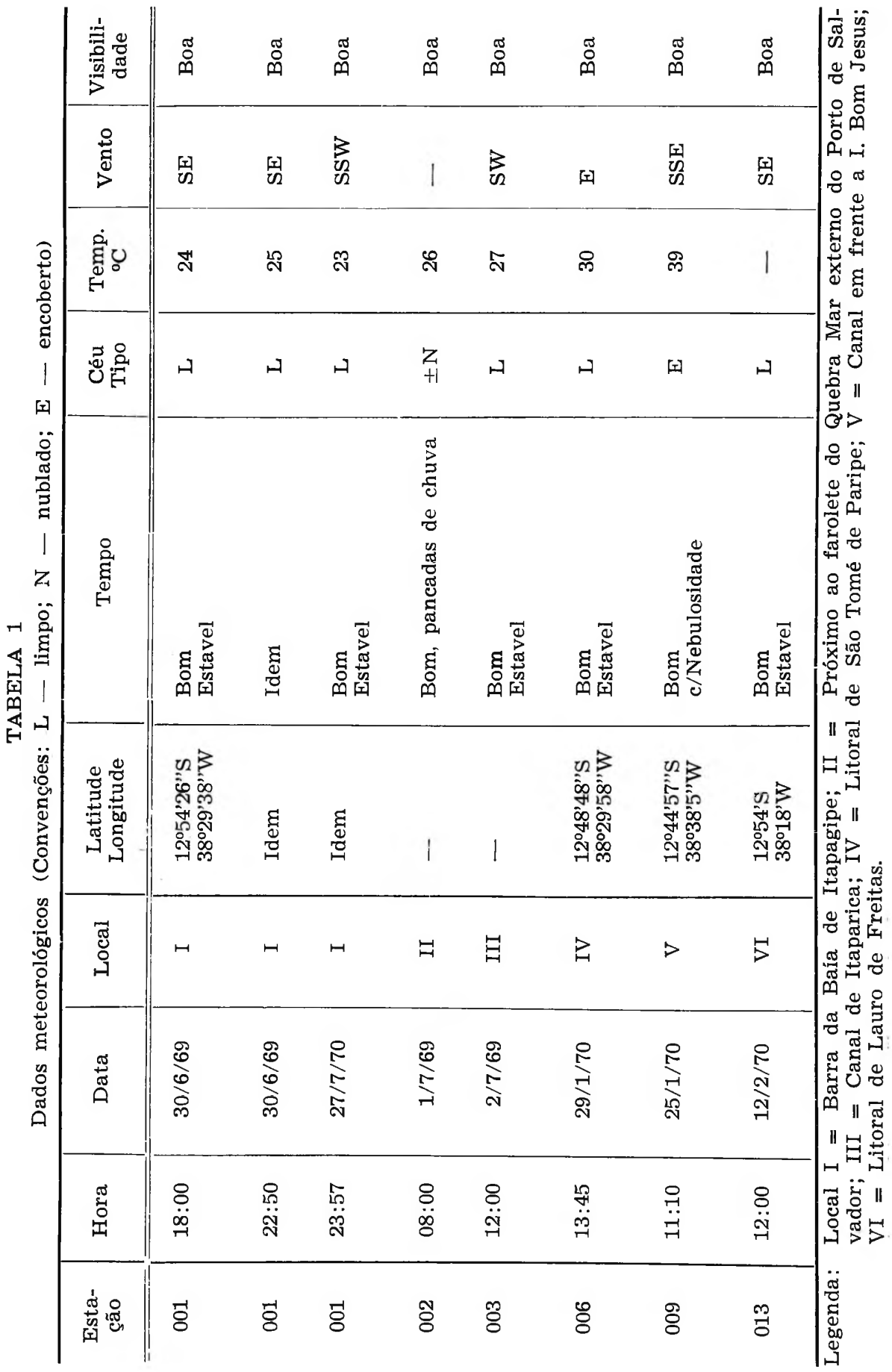




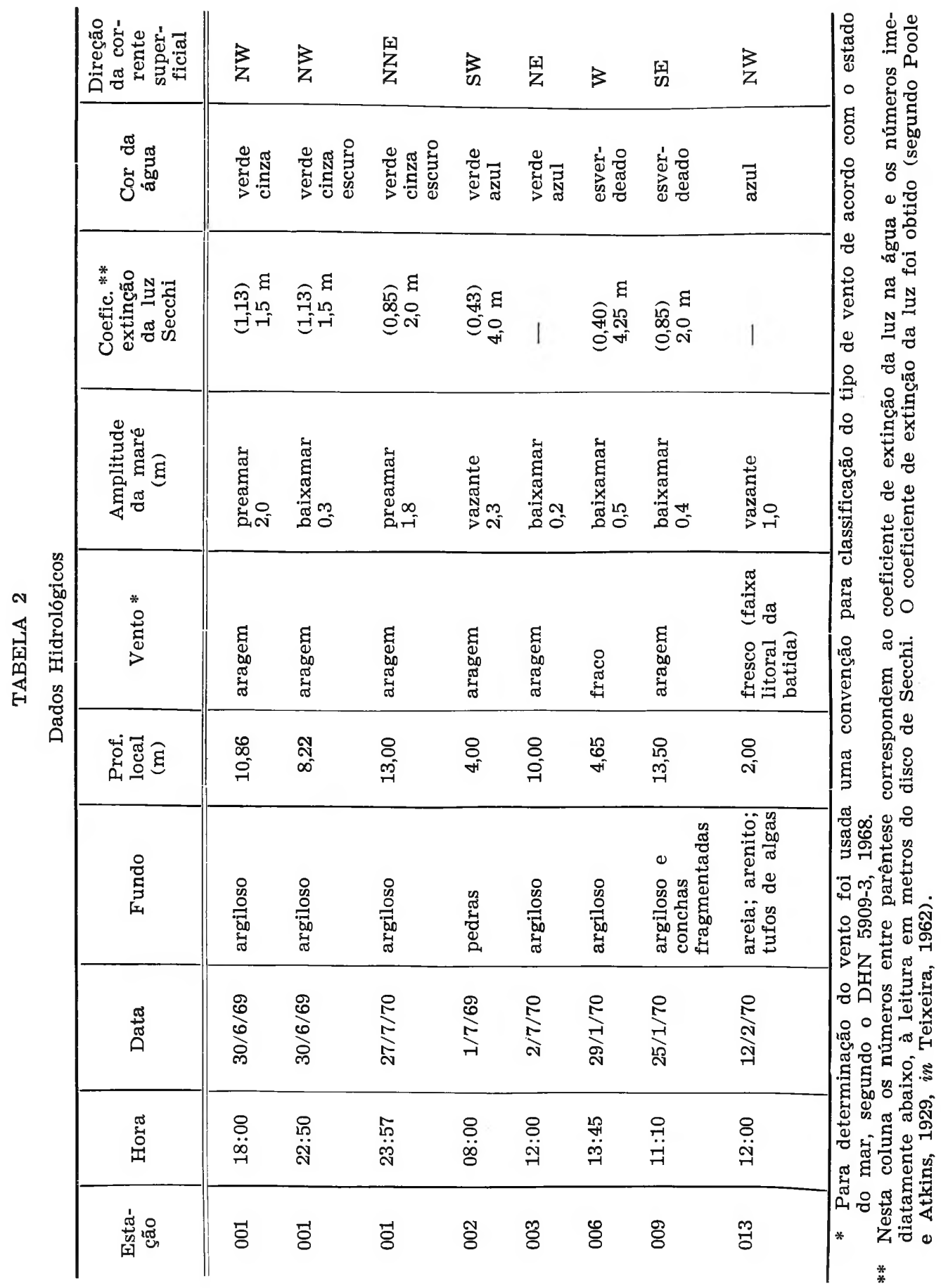




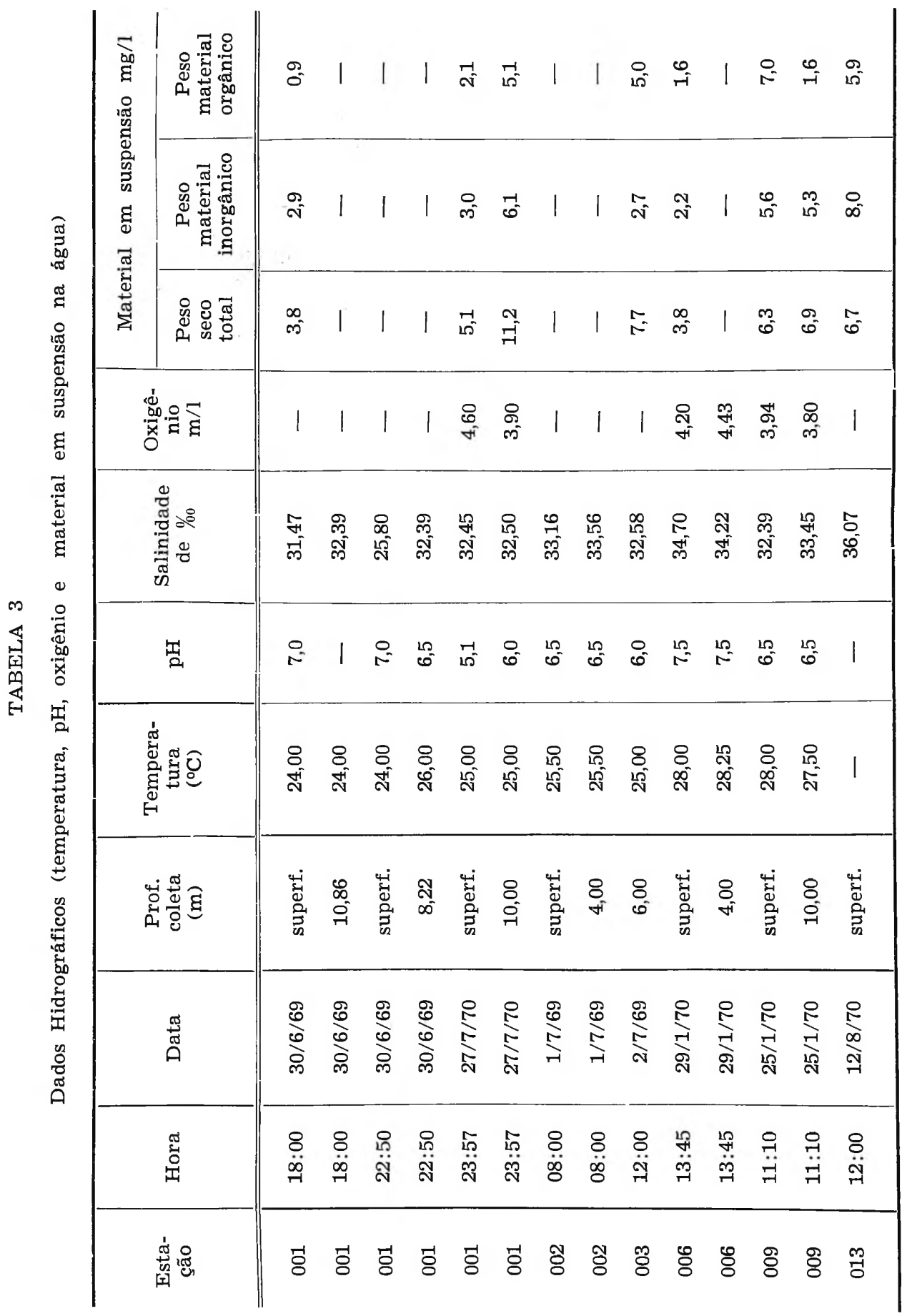




\section{F I T O P L Ã N C T O N \\ TABELA 4}

Estações nas quais foram coletadas amostras contendo fitoplanctontes

\begin{tabular}{c|c|c|c|c|c}
\hline $\begin{array}{c}\text { Esta- } \\
\text { cão }\end{array}$ & $\begin{array}{c}\text { Amos- } \\
\text { tra }\end{array}$ & Local & Data & Hora & Tipo de coleta \\
\hline 001 & 600 & Barra B. Itapagipe & $30 / 6 / 69$ & $18: 00$ & horizontal \\
001 & 601 & Idem & Idem & $22: 50$ & horizontal \\
002 & 602 & Farol do Quebramar & & \\
& & (Porto de Salvador) & $1 / 7 / 69$ & $08: 00$ & horizontal \\
003 & 603 & Canal de Itaparica & $2 / 7 / 69$ & $12: 00$ & horizontal \\
001 & 400 & Barra B. Itapagipe & $30 / 6 / 69$ & $18: 00$ & plâncton total \\
001 & 401 & Barra B. Itapagipe & $30 / 6 / 69$ & $22: 50$ & plâncton total \\
001 & 410 & Barra B. Itapagipe & $27 / 1 / 70$ & $12: 50$ & plâncton total \\
001 & 435 & Barra B. Itapagipe & $27 / 1 / 70$ & $23: 57$ & plâncton total \\
\hline
\end{tabular}

Lista 1: Fitoplanctones coletados na Baía de Todos os Santos:

Cyanophyceae - diversas colônias (estação 001);

Bacillariophyceae:

Melosira sp. (estação 001),

Skeletonema sp. (estação 001),

S'keletonema costatum (Grev.) (nas 5 estações),

Coscinodiscus sp. (nas 5 estações),

Coenobiodiscus muriformis Loeblich, Wight, e Darley (nas 5 estações),

Leptocylindrus sp. (estação 001),

Rhizosolenia sp. (nas 5 estações),

Chaetoceros sp. (nas 5 estações),

Chaetoceros coarctatus Lauder (estações 006, 009),

Streptotheca sp. (estação 001),

Ditylum brightwellei (West) (estações 002, 003),

Lithodesmium undulatum Ehrenb. (estação 001),

Triceratium favus Ehrenb. (em todas as estações),

Triceratium contortum Shabolt (nas 5 estações),

Biddulphia sp. (nas 5 estações)

Cerataulina sp. (estações 001, 002, 003 e 009),

Isthmia nervosa Kutz. (colonial) (estação 003), 
Hemidiscus (= Euodia) sp. (nas 5 estações)

Licmophora sp. (estação 001),

Thalassionema sp. (estações 001, 002, 003, 009),

Navicula sp. (estação 001),

Gyrosigma sp. (estações 001, 003, 006, 009),

Pleurosigma sp. (estações 001?, 003, 006, 009),

Phaeodactylum tricornutum (Bohlm) (estação 001),

Nitzschia sp. (estações 001, 002, 003),

Nitzschia longissima (Brèb.) (estação 001),

Nitzschia seriata Cleve (estação 001),

Diploneis sp. (estação 001);

Dinoflagellata:

Prorocentrum micans Ehrenb. (estação 001),

Ceratium pentagonum Gourret (estações 001, 002, 003),

Ceratium tripos Karsten (estações 001, 002, 003).

Lista 2: Zooplanctontes coletados na Baía de Todos os Santos:

Protozoa:

Globigerina bulloides d'Orbigny

Globorotalia menardii (d'Orbigny)

Nodosaria sp.

Milionella? sp.

Elphidium sp.

Stycholonche zanclea Hertwig

Vorticella marina Graeff

Tintinnopsis sp.

Favella sp.

Metazoa:

Euphysora gracilis (Brooks)

Ploctonide sp.

Phialidium haemisphaericum (L.)

Obelia sp.

Liriope tetraphylla Chamisso-Eisenhard

Physophorida

Calycophora

Mastigias scintillae Moreira

Convoluta sp.

Penilia avirostris Dana

Cypridina? 
Eucalanus pileatus Giesbrecht

Paracalanus aculeatus Giesbrecht

Paracalanus crassirostris Dahl

Paracalanus parvus Claus

Paracalanus sp.

Centropages furcatus Dana

Temora stylifera Dana

Pseudodiaptomus acutus (Dahl)

Calanopia americana Dahl

Labidocera fluviatilis Dahl

Acartia lilljeborgi Giesbrecht

Microsetella norvegica Boeck?

Clytemnestra rostrata Brady

Longipedia helgolandica Klie

Euterpina acutifrons Dana

Oithona hebes Giesbrecht

Oithona nana Giesbrecht

Oithona oculata Farran

Oithona ovalis Herbst

Oithona plumifera Giesbrecht

Oithona simplex Farran

Saphirella tropica Farran

Oncaea sp.

Corycaeus amazonicus Dahl

Corycaeus giesbrechti Dahl

Mysidacea

Amphipoda - Gammaridae

Sphaeroma sp.

Excorallana sp.

Epicaridae - larvas

Lucifer faxoni Borradaille

Sagitta friderici Ritter-Zahóny

Sagitta sp.

Salpa sp.

Oikopleura dioica Fol

Oikopleura longicauda Fol

Ovos e larvas: larva de Müller (Turbellaria), Pilidium, Mitraria, Nectochaeta, Rostraria, Trocophora e larvas de Spionidae, véligers de gasterópodos, jovens de gasterópodos, véligers e jovens de bivalvios (Mollusca), Acarina jovens, ovos de Centropages, náuplios de copé- 
podos, náuplios e Cypris de Cirripedia, larvas de Peltogaster, náuplios de lepadídeo, Alima (Stomatopoda), jovem de Diastylis?, larva de Epicarídea, Protozoea de Penaeus e outros, Zoea de Galatheidea, Paguridea e outros, Metazoea de Porcellanidae e outros, Mysis de vários crustáceos, Megalopa de vários crustáceos, Mastigopus de Sergestidae, larva de Lucifer; Actinotrocha; larva de Brachiopoda, Pluteus, Ophiopluteus e Echinopluteus, Tornaria, Amphioxides, ovos e alevinos de peixes.

Formas parasitárias e epibiônticas: Ellobiopsis sp., Epicaridae, outros epibiontes não identificados, diatomáceas epibiônticas, Vorticella marina sobre a diatomácea Chaetoceros coarctatus.

Ecdises: de Amphipoda, de Copepoda, de náuplios diversos, e de larvas de Lepas.

Dos fitoplanctontes dominaram sempre as diatomáceas. O nanoplâncton foi quantitativamente representado no inverno (1969) por diversos flagelados, inclusive Prorocentrum micans, e durante o verão (1970) predominou Phaeodactylum tricornutum. Nas amostras de plâncton total dominou no microfitoplâncton a Nitzschia seriata durante o inverno e em todas as amostras coletadas com rede de malha fina ocorreram em maior número principalmente Coscinodiscus sp., Hemidiscus sp., Biddulphia sp., Ceratium pentagonum e Ceratium tripos.

Na estação fora da Baía (013) Biddulphia sp. foi a mais numerosa. Chaetoceros coarctatus e Cerataulina sp. ocorreram em maior concentração nas estações 006 e 009 respectivamente. A diatomácea Coenobiodiscus muriformis, cujos gênero e espécie foram originalmente descritos (Loeblich et al., 1968) de exemplares da Baía de San Diego na California, é registrada pela primeira vez no Brasil.

TABELA 5

Estações nas quais foram feitas coletas horizontais do zooplâncton

\begin{tabular}{c|c|c|c|c}
\hline Estação & Amostra & Local & Data & Hora \\
\hline \hline 009 & 800 & Canal frente I. do Bom Jesus & $25 / 1 / 70$ & $11: 10$ \\
006 & 803 & Litoral de S. Tomé do Paripe & $29 / 1 / 70$ & $13: 45$ \\
013 & 805 & Litoral de Lauro de Freitas & $13 / 2 / 70$ & $12: 00$ \\
001 & 819 & Barra da Baía de Itapagipe & $27 / 7 / 70$ & $23: 57$ \\
\hline
\end{tabular}


O zooplâncton foi bem representado em todas as coletas. Nas amostras com rede de malha fina predominaram as formas pequenas, principalmente Oithonidae e Paracalanidae; meroplâncton, outros copépodos e protozoários. No plâncton coletado com rede de malha grossa predominaram as formas adultas, principalmente de copépodos e quetognatos.

A contagem proporcional do número de plânctontes para cada amostra mostrou sempre uma predominância para os copépodos, prevalecendo as formas de tamanho pequeno. Os copépodos achados em ordem de abundância decrescente estão assinalados na tabela 6 .

O meroplâncton foi sempre abundante, concordando estes resultados com os já encontrados em baías internas de outras regiões da costa brasileira.

Os plânctontes mais numerosos em ordem decrescente nas várias estações foram:

1) na 001 - Oithona hebes, Oithona ovalis, Favella sp., Oithona nana, náuplios de copépodos, Paracalanus crassirostris, Oithona simplex, véligers e jovens de biválvios e gasterópodos, Euterpina acutifrons, em coleta com rede de malha fina;

2) na 001 - em coleta com rede de malha grossa, predominaram Paracalanus sp., Eucalanus pileatus, Oithona oculata, Corycaeus amazonicus, Sagitta friderici, meroplâncton, Euterpina acutifrons, Lucifer faxoni;

3) na $002-P$. crassirostris, O. nana, náuplios de copépodos, Euterpina acutifrons, Paracalanus sp., meroplâncton, Sagitta friderici, Oikopleura sp., Corycaeus giesbrechti, C. amazonicus e O. simplex;

4) na $003-G$. simplex, náuplios de copépodos, P. crassirostris, $E$. acutifrons, náplios de cirripédios, Oikopleura sp., C. amazonicus, O. nana, Paracalanus sp. e Favella sp.;

5) na 006 - véligers e jovens de gasterópodos, Paracalanus sp., Oikopleura sp., Acartia lilljeborgi, Oithona oculata;

6) na 009 - véligers e jovens de gasterópodos, náuplios de cirripédios, $E$. acutifrons, $P$. crassirostris, véligers e jovens de biválvios, náuplios de copépodos, C. amazonicus, Paracalanus sp., Sagitta sp. e larvas de equinodermas; 
7) na 013 - meroplâncton, foraminíferos, P. crassirostris, Clytemnestra rostrata, tendo sido a última espécie registrada somente nesta estação.

Comparando o plâncton coletado na Baía de Todos os Santos ao de coletas feitas na costa fora dela (est. 013) verificou-se que a composição é mais rica dentro da Baía.

TABELA 6

Porcentagem de cada espécie no total de copépodos por amostra

\begin{tabular}{|c|c|c|c|c|c|c|c|c|}
\hline \multirow{2}{*}{$\begin{array}{l}\text { Estação } \\
\text { Amostras }\end{array}$} & \multicolumn{2}{|c|}{001} & \multirow{2}{*}{$\frac{002}{602}$} & \multirow{2}{*}{$\frac{003}{603}$} & \multirow{2}{*}{$\begin{array}{c}006 \\
803\end{array}$} & \multirow{2}{*}{$\begin{array}{c}009 \\
800\end{array}$} & \multirow{2}{*}{$\frac{013}{805}$} & \multirow{2}{*}{$\begin{array}{c}\text { Fre- } \\
\text { qüência } \\
\text { nas } \\
\text { amostras }\end{array}$} \\
\hline & 601 & 819 & & & & & & \\
\hline Espécies & $\%$ & $\%$ & $\%$ & $\%$ & $\%$ & $\%$ & $\%$ & \\
\hline Paracalanus sp. & - & 80,00 & - & - & 36,66 & - & 一 & $2 / 7$ \\
\hline P. crassirostris & 10,39 & - & 23,33 & 9,88 & 13,33 & 31,03 & - & $5 / 7$ \\
\hline O. simplex & 17,38 & - & 2,00 & 56,77 & - & - & - & $3 / 7$ \\
\hline Náuplios & 11,29 & - & 8,66 & 11,29 & - & 13,79 & - & $4 / 7$ \\
\hline E. acutifrons & 4,48 & 2,58 & 6,66 & 7,06 & 一 & 24,13 & - & $5 / 7$ \\
\hline o. hebes & 40,50 & - & - & - & - & - & - & $1 / 7$ \\
\hline O. oculata & 1,43 & 4,51 & - & - & 20,00 & - & - & $3 / 7$ \\
\hline A. lilljeborgi & 6,45 & 0,64 & - & 0,28 & 16,00 & 1,72 & - & $5 / 7$ \\
\hline o. nana & 2,50 & 0,64 & 19,33 & 2,54 & - & - & - & $4 / 7$ \\
\hline Copépodos jovens & - & - & 18,00 & 3,67 & 3,33 & - & - & $3 / 7$ \\
\hline C. amazonicus & - & 2,58 & 2,66 & 2,54 & - & 12,06 & 100,0 & $5 / 7$ \\
\hline C. furcatus & - & 2,58 & 3,33 & 0,28 & 3,33 & 1,72 & - & $5 / 7$ \\
\hline Paracalanus sp. & - & - & - & 1,97 & - & 8,62 & - & $2 / 7$ \\
\hline Centropages sp. & 2,15 & - & - & - & 3,33 & 3,44 & - & $3 / 7$ \\
\hline C. giesbrechti & - & 一 & 7,33 & - & - & - & - & $1 / 7$ \\
\hline Corycaeus sp. & - & - & 0,66 & 1,97 & - & 3,44 & - & $3 / 7$ \\
\hline$P$. parvus & - & - & 6,00 & - & - & - & 一 & $1 / 7$ \\
\hline E. pileatus & - & 5,16 & $\cdots$ & - & - & - & 一 & $1 / 7$ \\
\hline P. acutus & 2,68 & - & 1,33 & 0,28 & - & - & - & $3 / 7$ \\
\hline Eucalanus sp. & - & - & - & - & 3,33 & - & - & $1 / 7$ \\
\hline O. ovalis & 0,53 & - & - & 0,56 & - & - & - & $2 / 7$ \\
\hline Ovos & - & - & 0,66 & 0,28 & - & 一 & 一 & $2 / 7$ \\
\hline T. stylifera & - & 0,64 & - & - & 一 & 一 & - & $1 / 7$ \\
\hline C. americana & - & 0,64 & - & - & - & 一 & - & $1 / 7$ \\
\hline L. helgolandica & - & - & - & 0,56 & - & - & - & $1 / 7$ \\
\hline "S. tropica" & 0,17 & - & - & 0,28 & - & - & 一 & $2 / 7$ \\
\hline
\end{tabular}

\section{INTERPRETAÇÃO E DISCUSSÃO}

\section{Hidrologia:}

Com referência à meteorologia e hidrografia, parece que a Baia de Todos os Santos apresenta uma feição mais ou menos definida, 
pois há pouca variação na salinidade, na temperatura e na precipitação pluvial, com tendência ao equilíbrio estacional. Isto condicionaria uma estabilidade na composição do plâncton.

A grande área ocupada pela Baía, cerca de $800 \mathrm{~km}^{2}$ (DH1 Roteiro Brasil - Min. da Marinha, 1965) e sua posição geográfica em relação às correntes de águas costeiras, permite um intercâmbio destas com o sistema interno da Baía, havendo predominância de penetração de água costeira. Assim, se explicam os valores elevados de salinidade, mesmo nos pontos mais internos (Tabela 3). Além do mais, os rios que desembocam na Baía são em geral de pequeno porte, com exceção do Paraguassú (Mapa 1).

Pritchard (1955, 1967 in Tundisi, 1970) faz considerações sobre as variações nas condições ambientais dos estuários, concluindo Tundisi (1970) que a variabilidade dos parâmetros ambientais é a principal característica.

A Baía de Todos os Santos, onde a variação dos parâmetros ambientais é relativamente pouco acentuada, poderia ser considerada como um sistema complexo costeiro-lagunar, apresentando áreas estuarinas, principalmente nas regiões próximas à desembocadura de rios.

O tipo característico de água da área é pois a costeira, segundo os dados de temperatura e salinidade (Tabs. 1 e 3) encontrados (vide Emilsson, 1959).

$\mathrm{O} \mathrm{pH}$ das águas dentro da Baía de Todos os Santos variou de 6 a 7,5. Em Cananéia os valores foram de 6,6 a 8,4 (Kato, 1966; Teixeira, 1969) e no Recife de 6,5 a 8,4 (Ottmann e Ottmann, 1959; Okuda e Nobrega, 1960).- Os valores da Baía são mais baixos.

As quantidades de oxigênio (de 3,80 a $4,60 \mathrm{ml} / 1$ ) são intermediárias comparadas às de Cananéia (de 1,95 a 4,98 ml/1, seg. Texeira, 1969). Parecem indicar uma intensa atividade fotossintética para a Baía de Todos os Santos, e como as amostras foram feitas à superfície e na profundidade de $10 \mathrm{~m}$, estes resultados também seriam explicados pelo balanço entre a concentração de $\mathrm{O}_{2}$ na atmosfera e na água (Tab. 3).

Os resultados de coeficiente de extinção da luz (absorção da luz na água), cor e material em suspensão total na água indicam que a área é provavelmente enriquecida e que, em conseqüência, o volume de plâncton deve atingir valores bem acentuados (Tabs. 2 e 3). Isto 
é também confirmado pelo peso seco do material em suspensão (Tab. 3) que é muito elevado dentro da Baía. Os dados obtidos na Baía são menores (de 3,8 a $11,2 \mathrm{mg} / \mathrm{l}$ ) que os anotados em Cananéia (10,6 a $34,7 \mathrm{mg} / \mathrm{l}$, seg. Teixeira, 1969) onde predomina a formação vegetal denominada manguesal. Do lado de fora da Baía em águas oceânicas (Kanaeva, 1965) a quantidade de seston varia entre 100 e $50 \mathrm{mg} / \mathrm{m}^{3}$ portanto as águas aí são bem mais pobres. Os altos valores de material inorgânico principalmente na estação 013 (fora da Baia, na zona de arrebentação), são provavelmente causados pela pouca profundidade das águas e o movimento contínuo das mesmas. O caráter intermediário dos dados obtidos para as águas da Baía são provavelmente condicionados pela pouca variação de parâmetros ambientais nas áreas onde foram observados. Não há influência grande de rios como em Cananéia, onde também chove exageradamente. Influência forte de água oceânica de alta salinidade como no Recife, tão pouco foi observada.

O coeficiente de extinção da luz variou dentro da Baía de 0,40 a 1,13 da entrada às estações mais no fundo (Tab. 3). Comparados aos de Cananéia (Teixeira, 1969) mostraram-se mais baixos estes dados e portanto as águas da Baía são mais transparentes. Na Barra das Jangadas no Recife (Okuda, 1960) as águas são bastante turvas, variando os valores dados pela leitura do disco de Secchi, entre 0,15 e $1,0 \mathrm{~m}$, e portanto as águas são também menos transparentes que as da Baía. Estas são mais favoráveis à vida de plantas e animais aquáticos, pois, a vida destes "sofre talvez direta ou indiretamente alguma influência da turbidez considerável da água, que suscita uma diminuição da concentração de oxigênio dissolvido" (Okuda, op. cit.).

\section{Fitoplâncton:}

Os resultados do presente trabalho concordam com os encontrados em Cananéia (Kutner, comunicação pessoal e Teixeira, 1969) quanto ao aumento estacional específico de fitoplâncton, onde se verifica no inverno declínio de flagelados, Prorocentrum e Skeletonema costatum, e no verão dominância de Skeletonema costatum e Cheatoceros (diatomáceas). Na Baía de Todos os Santos ocorreu no inverno aumento de Nitzschia seriata e no verão de Skeletonema costatum e Chaetoceros no microplâncton. No nanoplâncton houve flagelados no inverno e no verão dominou Phaeodactylum tricornutum sobre os demais fitoplanctontes. 
Zimmermann (1916) faz referência a 35 espécies de diatomáceas coletadas na Baía de Todos os Santos, em Itapagipe e Ilha de Itaparica. Das diatomáceas então registradas ocorreram no levantamento feito agora: Navicula sp., Pleurosigma sp., Nitzschia longissima (Bréb.), Rhizosolenia sp., Biddulphia sp., Triceratium sp., Chaetoceros sp., Skeletonema costatum (Greville) e o gênero Coscinodiscus.

As diatomáceas predominantes durante o verão e inverno dentro da Baía são as usadas para criação de animais de laboratório (vide Allen e Nelson, 1910). Parece pois que estas águas são propícias nas épocas assinaladas para o desenvolvimento de zooplâncton. O estudo continuado durante vários anos de plâncton da Baía trará mais dados para confirmar ou não estes indícios sobre a riqueza desta área.

Hentschel (1933, mapa 4) situa o mar ao largo da costa baiana numa faixa onde predominam os peridíneos, os cocolitoforídeos e os protozoários em quantidades intermediárias e as diatomáceas em menor quantidade. Dentro da Baía a quantidade de diatomáceas $(97,47 \%$ do total de fitoplâncton) era maior que a de dinoflagelados $(0,13 \%$ do total de fitoplâncton) portanto o contrário do que foi observado ao largo. A diminuição da concentração em nutrientes parece relacionar-se com o aumento no número de dinoflagelados (Raymont, 1963). Pode-se portanto, inferir que as águas da Baía são mais ricas que as águas ao largo.

\section{Zooplâncton:}

Dos Foraminifera planctônicos registrados, predominou Globigerina bulloides, seguida por Globorotalia menardii. Estas duas espécies planctônicas estão presentes na costa do Brasil (Narchi, 1963).

A ocorrência de Foraminifera bentônicos Nodosaria sp., Millionella? , Elphidium sp., nas coletas superficiais, é explicada pela hidrodinâmica (Boltovskoy, 1965; Narchi, comunicação pessoal) ou seja devido a correntes ascendentes do fundo.

Elphidium é gênero que tolera bem água salobra e caracteriza regiões lagunares e águas interiores (Boltovskoy, 1965) portanto sua presença não é de estranhar na Baía. O mesmo podemos dizer de Globorotalia menardii, o qual pode ser indicador de águas quentes (Boltovskoy, 1965) e daí sua presença no plâncton baiano. Já a Globigerina bulloides, espécie de águas mais frias (Boltovskoy, 1965) ocorreu 
no plâncton baiano sob forma pequena e demonstra assim ser espécie muito euritérmica.

Stycholonche zanclea apesar de ocorrer no Mediterrâneo em águas de superfície durante a estação fria (Trégouboff, 1953) foi normalmente encontrada por mim e outros em águas costeiras e interiores do Brasil, não sendo de estranhar a sua ocorrência na Baía de Todos os Santos. O mesmo pode-se dizer de Favella e Tintinnopsis.

As medusas Liriope tetraphylla, e Obelia podem ocorrer em temperaturas que abrangem as da água da Baía $\left(21-23^{\circ} \mathrm{C}\right)$, isto é, de $16^{\circ} \mathrm{C}$ mais ou menos à mais de $25^{\circ} \mathrm{C}$. Liriope tetraphylla prefere água quente (Vannucci, 1957). Obelia é espécie característica de águas costeiras, sua ocorrência na Baía confirma a presença deste tipo d'água para a região. Phialidium hemisphaericum é também de águas costeiras, preferindo águas quentes provavelmente (Vannucci, op. cit.). Euphysora gracilis é indicadora de água de plataforma (Vannucci, 1963), sendo por isso interessante o registro de sua ocorrência dentro da Baía. Mastigias scintillae Moreira ocorreu em amostra da estação 009, porém aparece com freqüência em outros locais da Baía. Espécie originalmente descrita para São Paulo, surge ao largo do litoral sul do Brasil (Moreira, 1961) de janeiro a julho. Na Baía de Todos os Santos é abundante durante o verão (dezembro a fevereiro).

Convoluta sp. e Penilia avirostris são característicos de plâncton costeiro. No plâncton marinho brasileiro foram encontradas 2 espécies Convoluta henseni Böhmig e C. cenata Ev. Marcus, das quais a primeira é a mais frequente (Marcus, 1949 e Ev. Marcus, 1955).

Misidáceos, anfípodos e isópodos bentônicos ocorreram frequente. mente nas coletas noturnas, provavelmente por migração vertical.

Várias expedições coletaram copépodos ao largo da costa da Baía: “M. Lomonosov" (Björnberg, 1965) aos 1244'2” lat. S e 3501' long. W; "Calypso" (Gaudy, 1963) ; "Albatross" (Wilson, 1950), aos 1207' lat. S e 37'17' long. W, e "Meteor", ao largo da Baía de Todos os Santos, cujos Corycaeidae foram estudados por Klevenhusen (1933). Dos copépodos registrados nos trabalhos acima, encontrei os seguintes dentro da Baía: Paracalanus aculeatus Giesbr., Paracalanus parvus Claus, Temora stylifera Dana, Microsetella norvegica (Boeck?), Oithona nana (Giesbr.), Oithona plumifera Baird; Corycaeus giesbrechti F. Dahl, Centropages furcatus Dana; Clytemnestra rostrata Brady. Comparando a lista de espécies relacionadas por Björnberg (1965), Gaudy 
(1963), Wilson (1950), Klevenhusen (1933), com as registradas no presente trabalho, infere-se que a ocorrência de espécies costeiras no interior da Baía é determinada pela entrada de água costeira e que só ocasionalmente espécies oceânicas entram, principalmente as batipelágicas impossibilitadas pela pequena profundidade da Baía (máxima de $108 \mathrm{~m}$ e média de $23 \mathrm{~m}$ ). Quanto às espécies de águas interiores, principalmente Oithona hebes e $O$. ovalis, não suportariam a salinidade elevada da Corrente do Brasil (36 a 37\%0) e por este motivo não foram encontradas em mar aberto.

As espécies mais frequentes Euterpina acutifrons, Paracalanus crassirostris, Corycaeus amazonicus, Oithona hebes, O. ovalis, Longipedia helgolandica, Eucalanus pileatus e Centropagens furcatus são em parte as encontradas em Cananóia, de águas interiores (Teixeira et al. 1965), e em parte espécies costeiras e de água de plataforma (Björnberg, 1963), provando a grande influência da água de fora da Baía no seu interior. Mostra ainda seu caráter intermediário entre mares interiores, como o de Cananéia com grande influência de águas fluviais, e baías abertas em franca comunicação com o mar, como a de Santos (Carvalho, 1952). A Tabela 7 compara a lista de espécies de copépodos registrados em águas interiores da costa do Brasil e adjacências. E. vadicola e $E$. subcrassus encontrados na foz da Amazonas (F. Dahl, 1894) e na enseada do M. Virado (A. Prado, 1962) são provavelmente ocorrências de $E$. pileatus, o mais comum Eucalanus de águas marinhas brasileiras, pouco menor que $E$. subcrassus, típico do Pacífico.

Dos Decapoda predominaram frequentemente nas amostras as larvas. A forma adulta que ocorreu em maior quantidade na Baía foi Lucifer faxoni (vide Bowman e Holthuis, 1968). Tal espécie é típica de águas costeiras (Bowman e Mc Cain, 1967; Costa e Prandi, 1968; Barth e Costa, 1968). O gênero Lucifer é indicador de água quente (Barth, 1968) ocorrendo em águas desde a foz do Amazonas até o sul, Lagoa dos Patos (Barth, 1963; Barth e Costa, 1968).

A ocorrência da larva de Brachiopoda, semelhante à usualmente atribuida a Pelagodiscus atlanticus na Baía (est. 009) amplia a distribuição da mesma no plâncton ao largo da costa brasileira. Larvas de Brachiopoda foram vistas e coletadas pela primeira vez no mundo por F. Müller (in Müller, 1915) no Brasil ao largo de Santa Catarina. Adultos de Discinisca antillarum d'Orbigny vivem ao largo do Brasil 
(Thomson, 1927; De Fiori di Cropani, 1959). P. atlanticus (King) é cosmopolita (Thompson, op. cit.) e pode ocorrer aqui.

Dos Chaetognatha ocorreu Sagitta friderici, espécie eurihalina, euritérmica e costeira com vasta distribuição geográfica, "típica do Atlântico Oriental, Mediterrâneo e sudoeste Atlântico, sempre mais abundante em águas interiores que externas" (Alvariño, 1965).

Tavares (1967) identificou a salpa Thalia democratica em plâncton ao largo de São Paulo. Na Baía encontrei o gênero Salpa, mas, não cheguei a determinar a espécie. Também foi encontrado o gênero Oikopleura entre os tunicados planctônicos. $O$. dioica ocorreu em amostras da estação 001 e $O$. longicauda na estação 002. Ambas foram registradas em águas brasileiras por Björnberg e Forneris (1955) e podem ocorrer em águas costeiras.

Amphioxides foi encontrado na estação 001. O adulto é frequente no litoral adjacente, assim como Balanoglossus, cuja tornária também apareceu nas amostras.

A ocorrência de espécies de águas interiores é explicada pela proximidade das estações onde estas ocorrem, à desembocadura de rios. As espécies características de água oceânica são provavelmente introduzidas quando este tipo de água esporadicamente penetra no interior da Baía. O predomínio de espécies de água costeira dentro da Baía juntamente com os dados de temperatura e salinidade encontrados, permitem concluir que ocorre normalmente fluxo desta água para o interior da área estudada.

Espécies oceânicas típicas como Oithona plumifera, foram somente registradas numa estação próxima à barra da Baía (estação 002), comprovando o que foi dito acima.

Quanto à distribuição geográfica, a fauna de copépodos da Baía de Todos os Santos aproxima-se em composição à da Baía Fosforescente, Puerto Rico (Gonzalez e Browman, 1965). Esta semelhança é encontrada devido às condições hidrológicas, provavelmente parecidas. Secundariamente a fauna da Baía de Todos os Santos corresponde com a registrada na Enseada do Mar Virado, onde predomina a água costeira. Na tabela 7 pode ser verificada a correlação faunística.

As faunas da Foz do Tocantins e Cananéia diferem provavelmente pela grande concentração de água salobra e pela influência de água oceânica na primeira. 


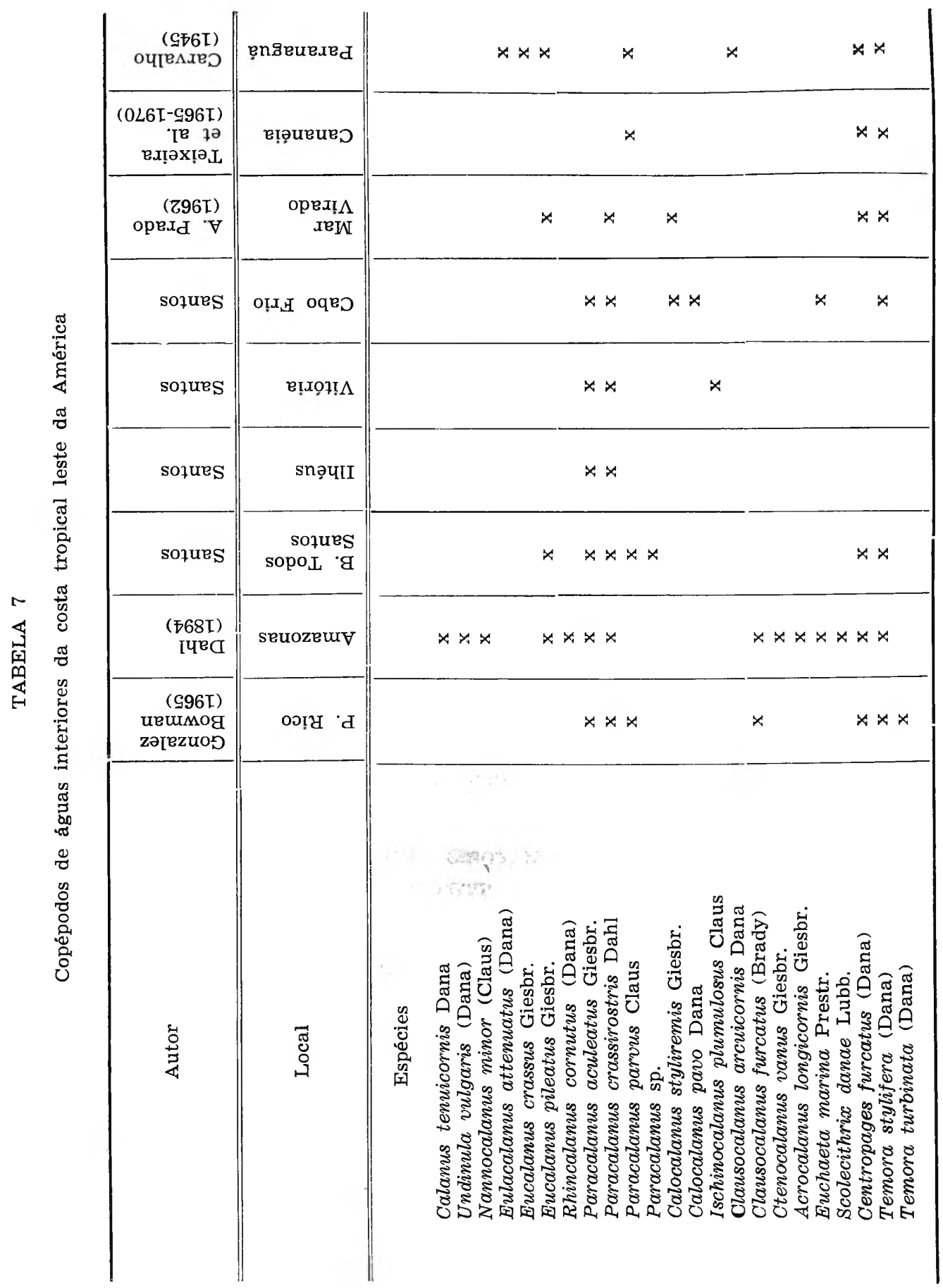




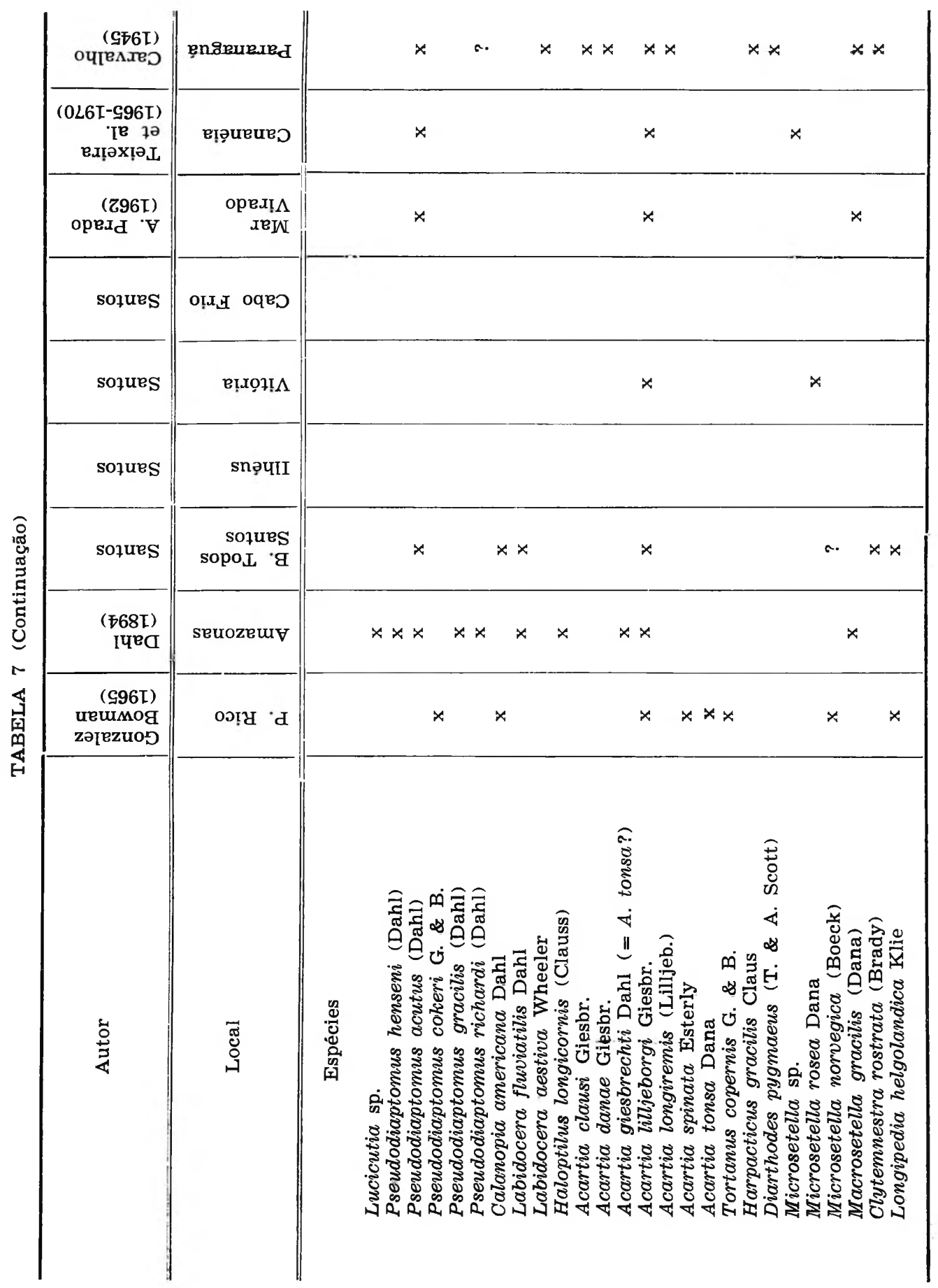




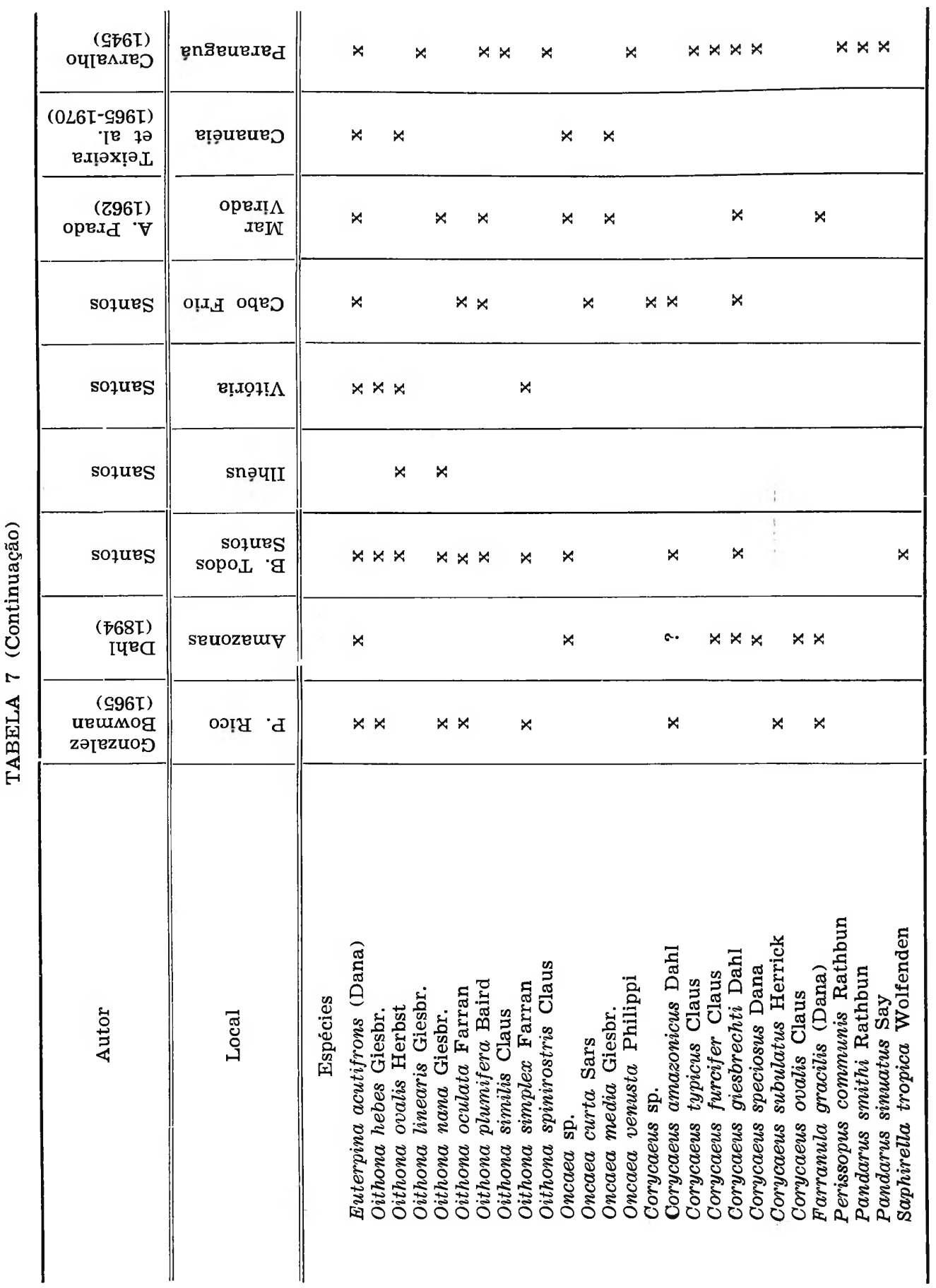


O pequeno número de espécies encontradas em Ihéus, Cabo Frio e Vitória foi motivado pelo pequeno número de amostragens. Futuras pesquisas completarão o número de dados para estas regiões.

\section{RESUMO E CONCLUSÕES}

Com a finalidade de investigar o plâncton da Baía de Todos os Santos (BA) foram realizadas coletas em várias localidades da mesma durante 1969-70. É apresentado aquí um breve histórico sobre os estudos planctonológicos realizados na área e regiões adjacentes. Foram tomados em cada estação dados meteorológicos, da hidrologia a temperatura, o oxigênio, o pH, a salinidade, o material em suspensão, a transparência da água, etc., amostras de plâncton com redes de malha fina e grossa e amostras de fitoplâncton total.

O levantamento dos planctontes foi feito.

Os dados apresentados são discutidos e comparados com resultados de outros ambientes marinhos, com especial referência aos copépodos.

Dos dados hidrológicos obtidos conclui-se que o tipo de águas predominante na região é a "água costeira", enriquecida no interior da baía pela drenagem de água doce do continente. O plâncton é proporcionalmente mais rico dentro da Baía, onde predominam as formas planctônicas de menor tamanho, do que fora dela, na costa atlântica.

Dos resultados obtidos, é inferido que a Baía de Todos os Santos apresenta uma composição planctônica caracteristicamente neritica com predomínio de fauna e flora costeiras, além de espécies estuarinas.

\section{BIBLIOGRAFIA CITADA}

ALLEN, J. E. \& NELSON, E. W. (1910) - On the Artificial Culture of Marine Plankton organisms. J. Mar. Biol. Ass. VIII (5) :421-474.

ALMEIDA PRADO, M. S. de (1961) - Chaetognatha encontrados em águas brasileiras. Bolm. Inst. Oceanogr., S. Paulo, Vol. XI, Fasc. 2:31-56.

(1962) - Sobre o Plâncton da enseada do Mar Virado e os seus métodos de coletas. Bolm. Inst. Oceanogr., S. Paulo, Vol. 12:49-68. 
ALVARIÑo, Angeles (1965) - Chaetognaths. Oceanogr. Mar. Biol. Ann. Rev., Harold Barnes Ed., V. 3, p. 115-194.

BARTH, R. (1963) - Estudos sobre Leucifer reynaudi como indicador de águas tropicais. Inst. Pesq. Marinha, Brasil. Notas Téc. n. ${ }^{\circ}$ 12, p. 1-16, Lam. 1-15.

(1968) - Resultados de Estudos em Indicadores Biológicos na Costa Brasileira. Inst. Pesq. Marinha. Brasil, n.0 019, p. 1-19+12 graf.

BARTH, R. \& COSTA, P. F. (1968) - Estudos sobre Leuciferinae na Região entre Recife e Cabo Orange. Inst. Pesq. Marinha Brasil., n. ${ }^{\circ}$ 030, p. 1-25 +12 Mapas + 5 Gráf.

BJöRNBERG, T. K. S. \& FORNERIS, L. (1955) - Resultados Científicos do Cruzeiro do "Baependí" e do "Vega" à Ilha de Trindade. Contrib. Avul. Inst. Oceanogr. S. Paulo, Ocean. Biol. n..$^{\circ}$, p. 3-68 + XVII estampas.

BJöRNBERG, T. K. S. (1963) - On the Marine Free-living Copepods off Brazil. Bolm. Inst. Oceanogr. S. Paulo, Vol. XIII, Fasc. 1:3-142.

- (1965) - The Study of Planktonic Copepods in the South West Atlantic. An. Acad. Bras. Cienc., Vol. 37, Supl.:219-230.

BOLTOVSKOY, E. (1965) - - Los Foraminiferos Recientes. Editorial Universitaria de Buenos Aires. 510 pp.

BOWMAN, T. E. \& Mc CAIN, J. C. (1967) - Distribution of the Planktonic Shrimp, Lucifer, in the Western North Atlantic. Bull. Mar. Sc., Vol. 17, No. 3: 660-671.

BOWMAN, T. E. \& HOLTHUIS, L. B. (1968) - Lucifer or Leucifer: Which Spelling is Correct? Crustaceana, Vol. 15, Part 2:216-217.

CAIN, A. J. (1954) - Animal Species and Their Evolution. Hutchinson's University Library. Hutchinson House, London, 'W. I., p. XI + 190 .

CARVALHO, J. de P. (1945) - Copépodos de Caiobá e baia de Guaratuba. Arq. Mus. Paranaense, Vol. 4:83-116.

(1952) - Sobre uma coleção de Copépodos ,não parasíticos, da baía de Santos e suas adjacências. Bolm. Inst. Oceanogr. S. Paulo, Vol. III, Fasc. 1 e 2:131-183.

COSTA, H. R. \& PRANDI, N. R. W. (1968) - Distribuição das espécies do gênero Lucifer em amostras de plâncton coletadas entre o Cabo Frio e a Baía de Santos. Resumos do III Congresso Brasileiro de Zoologia. Museu Nacional (Invertebrados 17).

DE FIORE DE CROPANI, O. C. (1959) - Sobre as larvas de Neotremata (Brachiópodos Inarticulados) da costa de São Paulo. Ciênc. e Cult., Vol. 11, n. ${ }^{\circ}$ $3: 149$.

DG 06 - IV (1960) - Levantamento oceanográfico da Costa Nordeste (agostooutubro de 1959). DHN. Ministério da Marinha, Brasil.

DG 16 (1969 e 1970) - Tábuas das Marés - Portos Brasileiros e Estrangeiros. DHN. Ministério da Marinha, Brasil.

DG 20 - III (1969) - III Com. Ocean., Perfis de Rio Doce à baía de Camamú. DHN. Ministério da Marinha, Brasil.

DAHL, F. (1894) - Die Copepodenfauna des unteren Amazonas. Bet. Naturf. Ges. Freiburg, 8:10-23. 
DH 1 (1265) - Roteiro do Brasil. DHN. Ministério da Marinha, Brasil.

DHN - 5909 - 3 (1968) - Estado do mar. Ministério da Marinha, Brasil.

EMILSSON, I. (1959) - Alguns aspectos físicos e químicos das águas marinhas brasileiras. Ciênc. e Cult., 11(2):44-45.

GAUDY, R. (1963) - Campagne du navire océanographique "Calypso" dans les eaux cotières du Brésil (Janvier-Février, 1962). Copépodes pélagiques. Rec. Trav. St. Mar. End., Bull. V 30(45):15-42.

GIESBRECHT, 'W. (1891) - Elenco dei Copepodi pelagici raccolti dal tenente di vascello Gaetano Chierchia duranti il viaggio della R. Corvetta "Vettor Pisani" negli anni 1882-1885, dal tenente di vascello Francesco Orgini nel Mar Rosso, nel 1884. Atti Rend. Accad. Iincei, Roma, ser. 4, vol. 7, sem. 1: 474-481.

(1892) - Systematik und faunistik der Pelagischen Copepoden. Fauna und Flora des Golfes von Neapel, Mon. 18, 831 p. + 54 taf.

GONZALEZ, J. G. \& BOWMAN, T. E. (1965) - Planktonic Copepods from Bahía Fosforescente, Puerto Rico, and adjacent Waters. Proc. U. S. Nat. Mus., vol. 117, n. $3513: 241-304$.

HARVEY, H. W. (1955) - The chemistry and fertility of sea waters. Cambridge, University Press, 217 p.

HENTSCHEL. E. (1933) - Allgemeine Biologie des Südatlantischen Ozeans. Wiss. Ergebn. Deuts. Atlant. Exped. "Meteor", 1925-1927, Bd. XI(1):1-168.

KANAEVA, I. (1965) - Sobre a distribuição quantitativa de plâncton no Atlântico, p. 333-343. In Relatórios do Inst. Pesquisa de Toda Uniāo das Pescas Marinhas e Oceanografia (U.N.I.R.O.), Vol. 57. Investigações em Conjunto com o Programa do Ano Geofísico Internacional, 2.a eđição. Casa Editora "Pishchevaya Promyshlennost", Moscou (em russo).

KÄSLER, R. (1938) - Die Verbreitung der Dinophysiales im Südantlantischen Ožean. Wiss. Ergebn. Deuts. Atlant. Exped. "Meteor", 1925-1927, Bd. XII, Fasc. 2(3):22-237.

KATO, K. (1966) - Chemical investigations on the hydrographical system of Cananéia lagoon. Bolm. Inst. Oceanogr. S. Paulo, Vol. 15, n. ${ }^{\circ}$ 1:1-12.

KIEFER, F. (1936) - Brasilianische Ruderfusskrebse (Crustacea Copepoda), gesammelt von Herrn Otto Schubart, 3: Zur Kenntniss der Oithona hebes Giesbrecht. Zool. Anz., Vol. 114, n.o 11-12:320-322.

KLEVENHUSEN, W. (1933) - Die Bevölkerung des Südatlantisehen Ozeans mit Corycaeen. Wiss. Ergebn. Deuts. Atlant. Exped. "Meteor" 1925-1927, Bd. XII, Fasc. 2:70-110.

LELOUP E. \& HENTSCHEL, E. (1935) - Die Verbreitung der Calycophoren Siphonophoren in Südatlantischen Ozean. Wiss. Ergebn. Deuts. Atlant. Exped. "Meteor", 1925-1927, Bd. XII, Fasc. 2(1):1-32.

LOEBLICH, A. R.; WIGHT, W. W. \& DARLEY, W. M. (1968) - A unique colonial marine centric diatom, Coenobiodiscus muriformis gen. et sp. nov. J. Phycol., vol. 4:23-29.

MARCUS. Ernesto (1949) - Turbellaria Brasileiros. Zoologia 14. Bolm. Fac. Fil. Cienc. Let. USP, S. Paulo: 7-156.. 
MARCUS, Eveline du Bois-Reymond (1955) - On Turbellaria and Polygordius trom the Brazilian Coast. Zoologia 20. Bolm. Fac. Fiol. Cienc. Let. USP, S. Paulo, n. ${ }^{\circ}$ 207:19-53.

MöLLER, A. (1915) - Fritz Müller - Werke, Briefe und Leben, Vol. 1 - Gesammelte Schriften. Text - Abt. 1: Arbeiten aus den Jahren 1844-1879 (Nr. 1-124), p. 1-800, Verlag Gustav-Fischer, Jena.

MOREIRA, M. G. B. S. (1961) - Sobre Mastigias scintillae sp. nov. (Scyphomedusae, Rhizostomeae) das costas do Brasil. Sep. Bolm. Inst. Oceanogr. S. Paulo, Vol. XI, Fac. 2:5-30.

NARCHI, W. (1963) - Sobre Nonionidae, Globorotalidae e Orbulinidae Recentes do Brasil. Sep. Bolm. Inst. Oceanogr. S. Paulo, Vol. XII, Fasc. 3:23-48.

OKUDA, T. \& NOBREGA, R. (1960) - Estudo da Barra das Jangadas, Partes 1 e 2. Trabs. Inst. Biol. Mar. Oceanogr. Univ. Recife, Vol. 2, n. ${ }^{\circ}$ 1:175-192.

OTTMAN, F \& OTTMAN, J. M. (1959) - La Marée de salinité dans le Capibaribe, Recife, Brésil. Trabs. Inst. Biol. Mar. Oceanogr. Recife, Vol. 1, n.o 1: 39-49.

PETERS, N. (1932) - Biologische Sonderuntersuchungen. Die Bevölkerung des Südatlantischen Ozeans mit Ceratien. Wiss. Ergebn. Deuts. Atlant. Exped. "Meteor", 1925-27, Bd. XII, Fasc. 1, p. 1-69.

RAMIREZ, F. C. (1966) - Copépodos Calanoidos marinos del área de Mar deI Plata con la descripción de Pontella marplantensis n. sp. Bol. Inst. Biol. Mar. Mar del Plata, Argentina, n. ${ }^{\circ}$ 11:24.

RAYMONT, J. E. G. (1963) - Plankton and Productivity in the Oceans. Macmillan, New York, VIII + 660 p.

ROSE, M. (1933) - Copépodes pélagiques. Faune de France, vol. 26, P. Lechevalier, Paris, 374 p.

TAVARES, D. Q. (1967) - Occurrence of doliolids and salps during 1958, 1959 and 1960 off the São Paulo Coast. Bolm. Inst. Oceanogr. S. Paulo, Vol. 16, p. $87-94+2$ prs.

TEIXEIRA, C. \& KUTNER, M. B. (1962) - Plankton studies in a mangrove environment. I. First assessment of standing stock and principal ecological factors. Sep. Bolm. Inst. Oceanogr. S. Paulo, Vol. 12, n. ${ }^{\circ}$ 3:101-124.

TEIXEIRA, C.; TUNDISI, J. \& KUTNER, M. B. (1965) - Plankton Studies in a mangrove environment. II. The standing stock and some ecological factors. Bolm. Inst. Oceanogr. S. Paulo, Vol. XIV:33-41.

TEIXEIRA, C. (1969) - Estudo sobre algumas características do Fitoplâncton da região de Cananéia e o seu potencial fotossintético. Tese de Doutora' mento. Universidade de S. Paulo.

THOMSON, J. A. (1927) - Brachiopod Morphology and Genera (Recent and Tertiary). New Zealand Board of Science and Art. Wellington, N. Z. Dominium Museum, p. VI + 338, 2 pr.

TIZARD, T. H.; MOSELEY, H. N.; BUChANAN, J. Y. \& MURRAY, J. (1885) Narrative. Vol. 1, 1st Part. Rep. Sc. Res. Voyage of H. M. S. (Challenger" (1873-1876), p. LIV + 509 
TRÉgoubofF, G. (1953) - Classe des Radiolaires in Traité de Zoologie. P. Grassé Ed. Tomo 1, Fasc. 2:321-388.

TUNDISI, J. G. (1970) - O plâncton estuarino. Contr. Inst. Oceanogr. Univ. S. Paulo, ser. Ocean. Biol. n. ${ }^{\circ}$ 19:1-22.

VANNUCCI, M. (1957) - On Brazilian Hydromedusae and their distribution in relation to different water masses. Bolm. Inst. Oceanogr. S. Paulo, vol. 7, fasc. 1-2:23-109.

(1963) - On the Ecology of Brazilian Medusae at $25^{\circ}$ lat. S. Bolm. Inst. Oceanogr. S. Paulo, Vol. 13, Fasc. 1:143-184.

WELLERSHAUS, S. (1969) - On the Taxonomy of Planktonic Copepoda in the Cochin Backwater (a South Indian Estuary). Veröf. Inst. Meeresforsch. Bremerhaven, Vol. 11:245-286.

WILSON, C. B. (1950) - Contributions to the biology of the Philippine Archipelago and Adjacent Regions. Copepods gathered by the U. S. Fisheries Steamer "Albatross" from to 1887 to 1909 , chiefly in the Pacific Ocean. U. S. Nat. Mus. Bull. n. ${ }^{\circ}$ 100, Vol. 14, part 4:141-441, 36 pls.

ZIMMERMANN, C. (1916) - Flora Diatomologica - Salvador. An. 5. Congr. Bras. Geogr. 1:448-461. 
